\title{
Correlation of Mandibular Incisor Inclination to Marginal Bone Levels and Cortical Bone Thickness in Different Skeletal Patterns: A Retrospective, Cone Beam Computed Tomography Study
}

\author{
${ }^{1}$ Narula Khyati, ${ }^{2}$ Asavari L Desai, ${ }^{3}$ Supriya Nambiar, ${ }^{4}$ Srikant Natarajan, ${ }^{5}$ Siddarth Shetty
}

\begin{abstract}
Introduction: Biologic factors, such as the cortical bone thickness and supporting bone as well as biomechanical factors, such as proclined teeth are closely interrelated. These factors often determine the potential deleterious effects of orthodontic treatment, such as gingival recession, dehiscence, fenestration, and external root resorption. The alveolar bone thickness and bone levels vary in different facial patterns and here in this study, we are finding if there is any correlation of these to tooth inclinations.
\end{abstract}

Aims and objectives: To assess the influence of mandibular incisor inclination on cortical bone thickness and alveolar bone levels in different skeletal patterns.

Materials and methods: Thirty cone beam computed tomography $(\mathrm{CBCT})$ scans and lateral cephalograms of pretreatment patients were analyzed with different skeletal patterns (10 each) for their alveolar bone height, alveolar bone thickness, and cortical bone thickness at mid root level and mandibular incisor inclination. Inclination and thickness were compared among the three groups and were correlated.

Results: Although there are wide variations, cortical bone thickness at mid root level in vertical, horizontal, and average growth pattern lingually and labially were $2.3 \pm 0.29 \mathrm{~mm}, 2.4 \pm$ $0.42,2.2 \pm 0.39$, and $0.69 \pm 0.12,0.65 \pm 0.23$, and $0.59 \pm 0.37$ respectively, and these values were not statistically significant. The vertical alveolar bone height did not hold any significance in our study. The incisor-mandibular plane angle (IMPA) for evaluating growth patterns was found to be significant.

Clinical significance: The inclination of the mandibular incisors is an important diagnostic consideration and has to be kept in mind during treatment planning. Excessive proclination of the incisors can lead to dehiscence, fenestration, as well as recession. Therefore, it becomes important to know the thickness of the bone as well as the marginal bone level to help us to use appropriate biomechanics.

${ }^{1-3,5}$ Department of Orthodontics, Manipal College of Dental Sciences, Mangaluru, Karnataka, India

${ }^{4}$ Department of Oral Pathology, Manipal College of Dental Sciences, Mangaluru, Karnataka, India

Corresponding Author: Asavari L Desai, Department of Orthodontics, Manipal College of Dental Sciences, Mangaluru Karnataka, India, Phone: +919483363045, e-mail: asavari. laxman@manipal.edu/desaiasavari@gmail.com
Conclusion: The mandibular incisor inclination and growth pattern of the patient appear to have no significant impact on the alveolar bone levels and cortical bone thickness. However, studies with a larger sample size and with high-dose CBCT are warranted.

Keywords: Cortical bone thickness, Incisor inclination, Skeletal growth patterns.

How to cite this article: Khyati N, Desai $A L$, Nambiar $S$, Natarajan S, Shetty S. Correlation of Mandibular Incisor Inclination to Marginal Bone Levels and Cortical Bone Thickness in Different Skeletal Patterns: A Retrospective, Cone Beam Computed Tomography Study. World J Dent 2018;9(4):291-296.

Source of support: $\mathrm{Nil}$

Conflict of interest: None

\section{INTRODUCTION}

Biologic factors of bone and its associated biomechanical implications determine the potential deleterious effects of orthodontic treatment. The IMPA introduced by Tweed is an important diagnostic measurement and has been used as a treatment goal in orthodontics for decades. A significant change in incisor angulation is important clinically, as it influences the esthetic profile of the patient, health of the supporting soft tissues, and long-term treatment stability. Studies have found that in patients needing retraction of the maxillary incisors to close extraction spaces, the lingual alveolar bone thickness decreases significantly. ${ }^{1}$ The patient's skeletal growth pattern is strongly correlated with alveolar bone thickness, with high mandibular angle cases showing thinner bone labial to the mandibular incisors and low mandibular plane angle cases displaying thicker bone lingual to maxillary and mandibular incisors. ${ }^{2}$

Hence, it becomes essential to establish the protrusive limits of the mandibular incisors before treatment, especially in patients with severe skeletal malocclusions where incisor movement is limited by the health of the periodontal tissues. ${ }^{3,4}$ Various studies have shown that direct relationship exists between thinness of the alveolar bone and increased facial and alveolar height, presumably because it becomes necessary for the incisors to continue to erupt in order to maintain overbite. The 
alveolus, in turn, becomes attenuated with thinning of the width between the labial and lingual walls. Lund et $\mathrm{al}^{5}$ in a previous study, evaluated premolar extraction patients, and found that $84 \%$ of the lingual surfaces of the lower central incisors showed a decrease in the bone height of more than $2 \mathrm{~mm}$, with an average of $5.7 \mathrm{~mm}$ on the lingual aspect and an increase of $0.8 \mathrm{~mm}$ on the buccal aspect of the same tooth. Experimental evidence also suggests that proclination of mandibular incisors can lead to vertical bone loss. ${ }^{6}$

Periapical radiographs and bitewing radiographs were the conventional means of assessing the vertical bone levels which themselves have their own limitations but with the advent of CBCT, most of these have been overcome. The CBCT images are devoid of any distortion and superimposition errors, thus enabling accurate quantitative and qualitative evaluation of the relationship between bone and teeth. ${ }^{7,8}$

Previous studies done using CBCT have either measured the bone levels or the alveolar bone thickness; both these parameters have never been studied together. Keeping this in mind, this study was taken up to assess the influence of mandibular incisor inclination on alveolar bone levels and cortical bone thickness in different skeletal patterns.

\section{MATERIALS AND METHODS}

This study was conducted over a span of 2 months, after obtaining Institutional Ethics Committee approval. Thirty pretreatment $\mathrm{CBCT}$ scans were analyzed, of which 9 were male and 21 were female subjects between 16 and 30 years of age. The subjects were selected irrespective of malocclusion they presented with. Subjects with (1) unerupted or missing mandibular permanent incisors, (2) periradicular or periapical pathologies/radiolucencies of either periodontal or endodontic origin in relation to mandibular anteriors, and (3) history of previous orthodontic treatment or any significant medical history, were excluded from the study.

All lateral cephalograms were taken in the natural head position, checked with a true vertical line. The growth pattern of the patient was assessed using SN-MP (Steiner's analysis) (Table 1 and Fig. 1).

The patients were grouped into three categories depending on the growth pattern:

1. Group I: Ten patients with horizontal growth pattern.

2. Group II: Ten patients with average growth pattern.

3. Group III: Ten patients with vertical growth pattern.

The mandibular incisor inclination was checked using IMPA.

Baseline diagnostic CBCT images acquired for clinical purposes in 30 subjects were selected. All low-dose $\mathrm{CBCT}$ scan images were taken as a routine diagnostic aid
Table 1: Definitions of variables used in lateral cephalogram and $\mathrm{CBCT}$

\begin{tabular}{ll}
\hline SN plane & $\begin{array}{l}\text { Sella to gnathion (Steiner's } \\
\text { analysis) }\end{array}$ \\
\hline $\begin{array}{l}\text { Lower gonial angle through } \\
\text { nasion }\end{array}$ & $\begin{array}{l}\text { Articulare-gonion-gnathion with } \\
\text { bisector } \\
\text { Mandibular plane (Tweed) } \\
\text { Tangent to lower border of } \\
\text { mandible }\end{array}$ \\
IMPA & Incisor mandibular plane angle \\
MBC-Bu & Labial marginal bone crest \\
MBC-Li & Lingual marginal bone crest \\
Buccal cortical thickness & Distance between inner and \\
cortical plates & outer buccal \\
Lingual cortical thickness & Distance between inner and \\
cortical plates & outer lingual \\
Marginal bone levels & Distance from CEJ to \\
& constructed menton \\
\hline
\end{tabular}

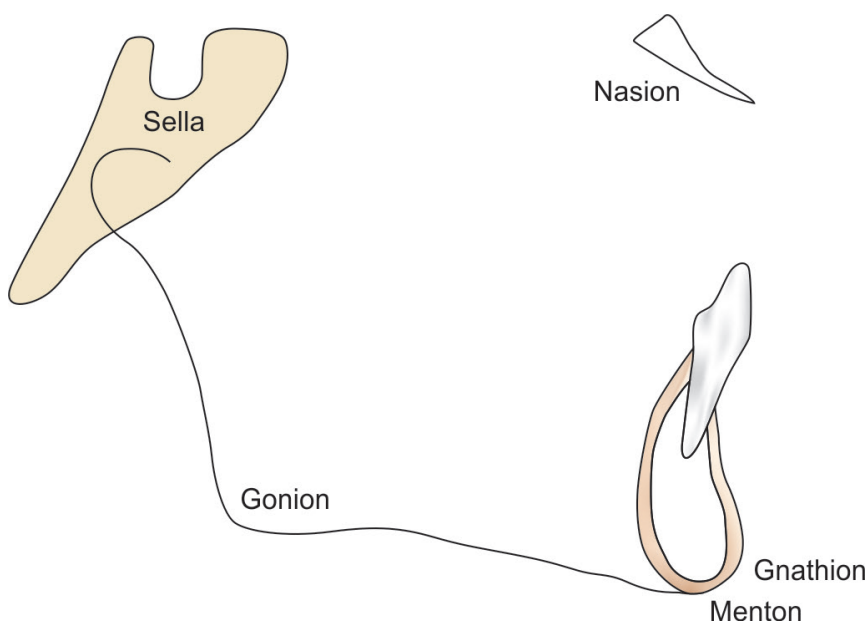

Fig. 1: Schematic diagram showing cephalometric parameters used

in our department at Manipal College of Dental Sciences (MCODS), Mangaluru. For the CBCT, each subject was made to stand in an upright position with the machine's laser light being denoted as FH plane. This was adjusted such that it was parallel to the floor. All the CBCTs were taken on Planmeca Promax 3 D Mid Pro Face (Helsinki Finland; $0.6 \mathrm{~mm}$ layer and $0.6 \times 0.6 \times 0.6$ voxel size) machine having current of $5.6 \mathrm{~mA}$, exposure time of 16 to 18 seconds, and voltage of $90 \mathrm{kVp}$, in the Department of Oral Medicine and Radiology, MCODS, Mangaluru. The data were saved as digital imaging and communications in medicine files which were later exported to Romexis 4.1 software for analyzing the images.

All measurements were done on the three-dimensional (3D) reconstructed images using the measuring scale tool in Romexis software itself. All three planes were oriented simultaneously to prevent any error. The sagittal section was used to do all the measurements. The thickness of the cortical bone was measured at the mid root and apical root level. The constructed line through menton was taken as a reference to measure bone levels 


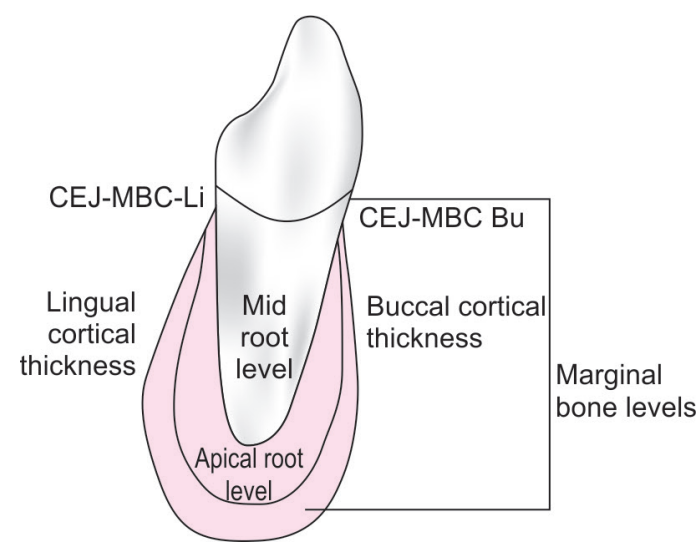

Fig. 2: Schematic diagram representing measurements from CBCT

by dropping the line straight to this line. The alveolar bone height was measured from alveolar crest to 3D constructed Me point and from the cementoenamel junction (CEJ) to Me point in the sagittal section of CBCT scans. The distance from CEJ to alveolar process was taken in normal limits of 1 to $3 \mathrm{~mm}$ and beyond $3 \mathrm{~mm}$, it was considered as marginal alveolar loss. Measuring bone thickness at both mid root and apical levels was done by keeping the scale angulated in the direction of alveolar process and tooth inclination, at both labial and lingual sides. In two of our samples, the alveolar process at the labial side was not appreciated much; hence, measurement was done in axial section (Fig. 2).

\section{Statistical Analysis}

The sample size at $95 \%$ confidence level, $80 \%$ power was calculated using the Statistical Package for the Social Sciences software (version 17; IBM, Armonk, New York). Tooth inclination and bone thickness were compared among the three groups using one-way analysis of variance (ANOVA) and post hoc Tukey test. Incisor inclination and the bone thickness were correlated using Pearson's correlation $(\mathrm{p}<0.05)$.

\section{RESULTS}

The results in one-way ANOVA showed no significance in cortical bone thickness at mid root level in vertical, horizontal, and average growth pattern both lingually and labially. The only value which held significance in our study was IMPA and lower gonial angle (Table 2).

\section{Alveolar Height}

Post hoc Tukey tests comparing vertical and horizontal groups showed a mean difference of 0.076 and was not statistically significant with a p-value of 0.997 . Comparing vertical and average growth pattern groups showed a mean difference of 0.142 and was not statistically significant with a p-value of 0.99. Comparing horizontal and average groups showed a mean difference of 0.066 , which was statistically insignificant (Table 3).

Table 2: Statistics for different variables using one-way ANOVA test

\begin{tabular}{|c|c|c|c|c|c|c|c|}
\hline & Growth pattern & $n$ & Mean & Std. deviation & $\begin{array}{l}\text { Statistics/mean } \\
\text { squares }\end{array}$ & $\begin{array}{l}\text { df2 (Welch)/F } \\
\text { (ANOVA) }\end{array}$ & $p$-value \\
\hline \multirow[t]{4}{*}{ Lower gonial angle } & Vertical & 10 & 78.5 & 2.461 & 361.633 & 71.48 & $<0.001$ \\
\hline & Horizontal & 10 & 66.5 & 2.593 & & & \\
\hline & Average & 10 & 73.2 & 1.549 & & & \\
\hline & Total & 30 & 72.73 & 5.445 & & & \\
\hline \multirow[t]{4}{*}{ Alveolar height } & Vertical & 10 & 23.663 & 3.302467 & 0.009 & 17.031 & 0.991 \\
\hline & Horizontal & 10 & 23.587 & 1.721208 & & & \\
\hline & Average & 10 & 23.521 & 1.597696 & & & \\
\hline & Total & 30 & 23.59033 & 2.258274 & & & \\
\hline \multirow[t]{4}{*}{ Lingual cortex thickness } & Vertical & 10 & 2.31 & 0.299258 & 0.16 & 1.131 & 0.337 \\
\hline & Horizontal & 10 & 2.458 & 0.421104 & & & \\
\hline & Average & 10 & 2.206 & 0.398029 & & & \\
\hline & Total & 30 & 2.324667 & 0.378224 & & & \\
\hline \multirow[t]{4}{*}{ Total alveolus thickness } & Vertical & 10 & 6.672 & 0.822149 & 0.294 & 0.315 & 0.732 \\
\hline & Horizontal & 10 & 6.907 & 1.304659 & & & \\
\hline & Average & 10 & 7.006 & 0.6509 & & & \\
\hline & Total & 30 & 6.861667 & 0.943292 & & & \\
\hline \multirow[t]{4}{*}{ Labial cortex thickness } & Vertical & 10 & 0.691 & 0.127754 & 0.025 & 0.363 & 0.699 \\
\hline & Horizontal & 10 & 0.653 & 0.236364 & & & \\
\hline & Average & 10 & 0.591 & 0.371676 & & & \\
\hline & Total & 30 & 0.645 & 0.258907 & & & \\
\hline \multirow[t]{4}{*}{ IMPA } & Vertical & 10 & 94.5 & 8.37 & 320.633 & 4.299 & 0.024 \\
\hline & Horizontal & 10 & 105.8 & 10.064 & & & \\
\hline & Average & 10 & 100.8 & 7.239 & & & \\
\hline & Total & 30 & 100.37 & 9.568 & & & \\
\hline
\end{tabular}


Table 3: Association between different variables using

Pearson's correlation

\begin{tabular}{|c|c|c|c|}
\hline \multicolumn{3}{|c|}{ Growth pattern } & \multirow{2}{*}{$\begin{array}{l}\text { IMPA } \\
-0.785\end{array}$} \\
\hline \multirow[t]{17}{*}{ Vertical } & \multirow{3}{*}{$\begin{array}{l}\text { Lower gonial } \\
\text { angle }\end{array}$} & Pearson's correlation & \\
\hline & & Sig. (2-tailed) & 0.007 \\
\hline & & $\mathrm{N}$ & 10 \\
\hline & \multirow[t]{3}{*}{ Alveolar height } & Pearson's correlation & 0.506 \\
\hline & & Sig. (2-tailed) & 0.136 \\
\hline & & $\mathrm{N}$ & 10 \\
\hline & \multirow{3}{*}{$\begin{array}{l}\text { Lingual cortex } \\
\text { thickness }\end{array}$} & Pearson's correlation & 0.250 \\
\hline & & Sig. (2-tailed) & 0.486 \\
\hline & & $\mathrm{N}$ & 10 \\
\hline & \multirow{3}{*}{$\begin{array}{l}\text { Total alveolus } \\
\text { thickness }\end{array}$} & Pearson's correlation & 0.291 \\
\hline & & Sig. (2-tailed) & 0.415 \\
\hline & & $\mathrm{N}$ & 10 \\
\hline & \multirow{3}{*}{$\begin{array}{l}\text { Labial cortex } \\
\text { thickness }\end{array}$} & Pearson's correlation & -0.034 \\
\hline & & Sig. (2-tailed) & 0.926 \\
\hline & & $\mathrm{N}$ & 10 \\
\hline & \multirow[t]{2}{*}{ IMPA } & Pearson's correlation & 1 \\
\hline & & $\mathrm{N}$ & 10 \\
\hline \multirow[t]{17}{*}{ Horizontal } & \multirow{3}{*}{$\begin{array}{l}\text { Lower gonial } \\
\text { angle }\end{array}$} & Pearson's correlation & 0.013 \\
\hline & & Sig. (2-tailed) & 0.972 \\
\hline & & $\mathrm{N}$ & 10 \\
\hline & \multirow[t]{3}{*}{ Alveolar height } & Pearson's correlation & -0.060 \\
\hline & & Sig. (2-tailed) & 0.870 \\
\hline & & $\mathrm{N}$ & 10 \\
\hline & \multirow{3}{*}{$\begin{array}{l}\text { Lingual cortex } \\
\text { thickness }\end{array}$} & Pearson's correlation & -0.285 \\
\hline & & Sig. (2-tailed) & 0.426 \\
\hline & & $\mathrm{N}$ & 10 \\
\hline & \multirow{3}{*}{$\begin{array}{l}\text { Total alveolus } \\
\text { thickness }\end{array}$} & Pearson's correlation & 0.158 \\
\hline & & Sig. (2-tailed) & 0.664 \\
\hline & & $\mathrm{N}$ & 10 \\
\hline & \multirow{3}{*}{$\begin{array}{l}\text { Labial cortex } \\
\text { thickness }\end{array}$} & Pearson's correlation & 0.530 \\
\hline & & Sig. (2-tailed) & 0.115 \\
\hline & & $\mathrm{N}$ & 10 \\
\hline & \multirow[t]{2}{*}{ IMPA } & Pearson's correlation & 1 \\
\hline & & $\mathrm{N}$ & 10 \\
\hline \multirow[t]{17}{*}{ Average } & \multirow{3}{*}{$\begin{array}{l}\text { Lower gonial } \\
\text { angle }\end{array}$} & Pearson's correlation & 0.281 \\
\hline & & Sig. (2-tailed) & 0.431 \\
\hline & & $\mathrm{N}$ & 10 \\
\hline & \multirow[t]{3}{*}{ Alveolar height } & Pearson's correlation & -0.079 \\
\hline & & Sig. (2-tailed) & 0.829 \\
\hline & & $\mathrm{N}$ & 10 \\
\hline & \multirow{3}{*}{$\begin{array}{l}\text { Lingual cortex } \\
\text { thickness }\end{array}$} & Pearson's correlation & 0.006 \\
\hline & & Sig. (2-tailed) & 0.987 \\
\hline & & $\mathrm{N}$ & 10 \\
\hline & \multirow{3}{*}{$\begin{array}{l}\text { Total alveolus } \\
\text { thickness }\end{array}$} & Pearson's correlation & 0.193 \\
\hline & & Sig. (2-tailed) & 0.593 \\
\hline & & $\mathrm{N}$ & 10 \\
\hline & Labial cortex & Pearson's correlation & 0.114 \\
\hline & thickness & Sig. (2-tailed) & 0.754 \\
\hline & & $\mathrm{N}$ & 10 \\
\hline & IMPA & Pearson's correlation & 1 \\
\hline & & $\mathrm{N}$ & 10 \\
\hline
\end{tabular}

\section{Lingual Cortex Thickness}

Comparison among the different growth patterns showed that lingual cortex thickness was not significantly correlated with any of the groups (Table 3).

\section{Total alveolus Thickness}

Post hoc Tukey tests comparing vertical and horizontal groups showed a mean difference of -0.235 and was not statistically significant with a p-value of 0.851 . Comparing vertical and average groups showed a mean difference of -0.334 and was not statistically significant with a p-value of 0.723 . Comparing horizontal and average groups showed a mean difference of -0.099 and was not statistically significant with a p-value of 0.972 (Table 3).

\section{Labial Cortex Thickness}

Post hoc Tukey tests comparing vertical and horizontal groups showed a mean difference of 0.038 and is not statistically significant with a p-value of 0.945 . Comparing vertical and average groups showed a mean difference of 0.1 and was not statistically significant with a $p$-value of 0.679. Comparing horizontal and average groups showed a mean difference of 0.062 and was not statistically significant with a p-value of 0.861 (Table 3).

\section{DISCUSSION}

Teeth may be decentralized from the alveolar bone envelope with orthodontic treatment, depending on the extent of tooth movement and the initial morphology of the alveolar bone. The decision as to what extent the lower incisors should be moved and how this will affect the associated bone is an important consideration in treatment planning. ${ }^{9}$ The average alveolar bone height from CEJ observed was $23.5 \pm 2.25 \mathrm{~mm}$. It had no significance in our study since no correlation could be found out between inclination and alveolus recession. Janson et $\mathrm{al}^{10}{ }^{10}$ in a previous study, used bitewings to assess posterior interdental vertical bone height and reported 0.5 and $0.13 \mathrm{~mm}$ of bone loss in orthodontically treated patients as compared with an untreated group.

Schudy ${ }^{11}$ has suggested that a good indicator of mandibular rotation is the inclination of the mandibular plane. In our study, the mandibular plane angle was used to categorize subjects into average-, low- and high-angle subgroups. Bjork ${ }^{12}$ and Nielsen ${ }^{13}$ observed that tooth eruption is almost vertical, whereas in patients with vertical growth pattern, more distal mandibular incisor eruption is observed.

In previous studies, it had been shown that pretreatment alveolar thickness is associated with vertical bone loss in patients treated orthodontically. ${ }^{14-16}$ However, in our study, it was seen in only one case that thin alveolus was associated with pretreatment recession, but overall results were nonsignificant. The results showed no significance in cortical bone thickness at mid root level in vertical, horizontal, and average growth pattern both lingually and labially. Garlock et $a{ }^{17}$ reported that thinner 
pretreatment cortical bone at the apex level was correlated with greater facial vertical bone loss, and movements of the mandibular incisor apex toward cortical bone produce greater amounts of vertical bone loss. Baysal et $\mathrm{al}^{9}$ concluded that lower incisor position and mandibular anterior bony support were different between averageand high-angle Class II patients.

The only value which held significance in our study was the IMPA and lower gonial angle. The vertical alveolar bone height did not show any significance in our study, nor was there any correlation between the variables.

Hoang et $\mathrm{al}^{18}$ compared the mandibular anterior alveolar housing in individuals with different mandibular plane angles before orthodontic treatment and measured the root resorption and alveolar bone loss post orthodontic treatment. The pretreatment anterior alveolar bone widths were wider in low-angle than in average- and high-angle individuals.

Probing, bitewing/periapical radiographs are used for the assessment of bony support. ${ }^{19}$ Conventional radiographic methods have some limitations, such as difficulty in reproducing the angles over time and superimposition of the anatomic structures. ${ }^{20}$ Moreover, an underestimation of the amount of actual bone loss has been reported. . $^{81}$

Cephalometric radiography has significant limitations for the assessment of alveolar bone thickness as well as incisor inclination, especially in the mandibular anterior alveolar region, since images of all structures overlap in $3 \mathrm{D}$ space, thereby giving rise to an important enlargement error due to divergence of the X-ray beam. A major advantage of $\mathrm{CBCT}$ over conventional radiography is its ability to evaluate real anatomy in 3D, true-to-scale images without superimpositions, or distortions of the neighboring structures. ${ }^{9}$ Furthermore, quantitative and qualitative evaluation of bone surfaces, quantitative evaluation of the relationship between teeth and bone, and the selection of the desired sections are possible due to secondary computerized reconstructions. ${ }^{19,21}$

A limited sample size and also the use of low-dose CBCT are a drawback of this study and could be a reason for not getting any positive correlation, as there is a tendency for over- or underestimating bone levels. Studies with a larger sample size using high-dose CBCT are warranted to assess the correlation of mandibular incisor inclination to bone thickness in different growth patterns.

\section{CONCLUSION}

The mandibular incisor inclination and growth pattern of the patient appear to have no significant impact on the cortical bone thickness and alveolar bone levels.

\section{REFERENCES}

1. Sarikaya S, Haydar B, Ciger S, Ariyürek M. Changes in alveolar bone thickness due to retraction of anterior teeth. Am J Orthod Dentofacial Orthop 2002 Jul;122(1):15-26.

2. Handelman CS. The anterior alveolus: its importance in limiting orthodontic treatment and its influence on the occurrence of iatrogenic sequelae. Angle Orthod 1996 Apr;66(2):95-109.

3. Yared KF, Zenobio EG, Pacheco W. Periodontal status of mandibular central incisors after orthodontic proclination in adults. Am J Orthod Dentofacial Orthop 2006 Jul;130(1):6. e1-6.e8.

4. Ten Hoeve A, Mulie RM. The effect of antero-postero incisor repositioning on the palatal cortex as studied with laminagraphy. J Clin Orthod 1976 Nov;10(11):804-822.

5. Lund H, Grondahl K, Grondahl HG. Cone beam computed tomography evaluations of marginal alveolar bone before and after orthodontic treatment combined with premolar extractions. Eur J Oral Sci 2012 Jun;120(3):201-211.

6. Batenhorst KF, Bowers GM, Williams JE Jr. Tissue changes resulting from facial tipping and extrusion of incisors in monkeys. J Periodontol 1974 Sep;45(9):660-668.

7. Yamada C, Kitai N, Kakimoto N, Murakami S, Furukawa S, Takada K. Spatial relationships between the mandibular central incisor and associated alveolar bone in adults with mandibular prognathism. Angle Orthod 2007 Sep;77(5):766-772.

8. Fuhrmann R. Three-dimensional interpretation of periodontal lesions and remodeling during orthodontic treatment. Part III. J Orofac Orthop 1996 Aug;57(4):224-237.

9. Baysal A, Ucar FI, Buyuk SK, Ozer T, Uysal T. Alveolar bone thickness and lower incisor position in skeletal Class I and Class II malocclusions assessed with cone-beam computed tomography. Korean J Orthod 2013 Jun;43(3):134-140.

10. Janson G, Bombonatti R, Brandao AG, Henriques JF, de Freitas MR. Comparative radiographic evaluation of the alveolar bone crest after orthodontic treatment. Am J Orthod Dentofacial Orthop 2003 Aug;124(2):157-164.

11. Schudy FF. The rotation of the mandible resulting from growth: its implications in orthodontic treatment. Angle Orthod 1965 Jan;35:36-50.

12. Bjork A. Variations in the growth pattern of the human mandible: longitudinal radiographic study by the implant method. J Dent Res 1963 Jan-Feb;42(1 Pt 2):400-411.

13. Nielsen IL. Vertical malocclusions: etiology, development, diagnosis and some aspects of treatment. Angle Orthod 1991 Winter;61(4):247-260.

14. Gracco A, Luca L, Bongiorno MC, Siciliani G. Computed tomography evaluation of mandibular incisor bony support in untreated patients. Am J Orthod Dentofacial Orthop 2010 Aug;138(2):179-187.

15. Garib DG, Yatabe MS, Ozawa TO, Filho OG. Alveolar bone morphology under the perspective of the computed tomography: defining the biological limits of tooth movement. Dent Press J Orthod 2010 Sep-Oct;15(5):192-205.

16. Thongudomporn $U$, Charoemratrote $C$, Jearapongpakorn $S$. Changes of anterior maxillary alveolar bone thickness following incisor proclination and extrusion. Angle Orthod 2015 Jul;85(4):549-554.

17. Garlock DT, Buschang PH, Araujo EA, Behrents RG, Kim KB. Evaluation of marginal alveolar bone in the anterior mandible with pretreatment and posttreatment computed tomography in nonextraction patients. Am J Orthod Dentofacial Orthop 2016 Feb;149(2):192-201. 
18. Hoang N, Nelson G, Hatcher D, Oberoi S. Evaluation of mandibular anterior alveolus in different skeletal patterns. Prog Orthod 2016 Dec;17(1):22.

19. Nauert K, Berg R. Evaluation of labio-lingual bony support of lower incisors in orthodontically untreated adults with the help of computed tomography. J Orofac Orthop 1999 Sep;60(5):321-334.
20. Misch KA, Yi ES, Sarment DP. Accuracy of cone beam computed tomography for periodontal defect measurements. J Periodontol 2006 Jul;77(7):1261-1266.

21. Fuhrmann RA, Wehrbein H, Langen HJ, Diedrich PR. Assessment of the dentate alveolar process with high resolution computed tomography. Dentomaxillofac Radiol 1995 Feb;24(1):50-54. 